\title{
Longitudinal Clinical Evaluation of Post Systems: A Literature Review
}

\author{
Carlos José SOARES \\ Andréa Dolores Correia Miranda VALDIVIA \\ Gisele Rodrigues da SILVA \\ Fernanda Ribeiro SANTANA \\ Murilo de Souza MENEZES \\ Department of Operative Dentistry and Dental Materials, Dental School, \\ UFU - Federal University of Uberlândia, Uberlândia, MG, Brazil
}

\begin{abstract}
In this survey, retrospective and prospective clinical studies dealing with cast-post-and core and fiber posts were reviewed regarding the rate of survival of restorations and the most prevalent failures. Electronic searches of the literature were performed in MEDLINE by crossing the key words: "Fiber post and clinical study", "Fiber post and clinical evaluation", "Cast post-and-core and clinical study", and "Root post and retrospective survival study". The cut-off dates were December 1990 through the end of December 2010. Review of literature showed that several interrelated biological, mechanical, and aesthetic factors are involved in the survival rate of restorative procedures in endodontically treated teeth, and post selection should fulfill and optimize these factors. Data based on long-term clinical studies are essential for the general practitioner when making clinical decisions. An adequate selection of teeth and post system must be made, and a minimal amount of existing tooth substance should be removed. A ferrule must be present for safe indication of the fiber posts. Fiber glass posts have demonstrated good survival in clinical studies, with similar performance to cast-post-and cores. Metallic posts have good clinical survival, but the associated failures are mostly irreversible, unlike what happens with the glass fiber posts.
\end{abstract}

Key Words: cast post-and-core, clinics investigations, fiber post, longitudinal evaluation.

\section{INTRODUCTION}

Endodontically treated teeth often require postand-core restorations for retention purposes because of extensive structural defects resulting from caries and access cavity preparation according to Heydecke and Peters (1). Preserving tooth structure is one of the most important factors in avoiding complications with intraradicular retention $(2,3)$.

In the last decade, cast post-and-core has been the most commonly used post type $(4,5)$. Unfortunately, several disadvantages are associated with conventional cast post-and-cores, such as loss of post retention $(6,7)$, root fractures (8), and risk of corrosion (9). During the preparation of teeth to receive cast post-and-core, larger amount of root dentin is removed, increasing the risk of tooth fracture (10). Stress concentration in the post and higher dentin strain have been verified in teeth restored with cast post-and-core and other metallic posts (11). The introduction of carbon or glass fiber post systems provided an alternative to cast or prefabricated metallic posts for the restoration of endodontically treated teeth (4). These post systems present similar mechanical properties to those of dentin, resulting in similar stress patterns as those of intact teeth (12-14). Additionally, root canal preparation for these types of post systems is more conservative (15).

Several retrospective and prospective studies have been performed to evaluate the survival rate of different post systems showing absence of tooth fracture when fiber posts were used to restore endodontically treated teeth $(4,16,17)$. Data based on long-term clinical studies are essential for the general practitioner when making clinical decisions (3). However, a small number of clinical studies and randomized controlled trials are available for analysis (2). According to Fokkinga et al.

Correspondence: Prof. Dr. Carlos José Soares, Grupo de Pesquisa Biomecânica, Faculdade de Odontologia, Universidade Federal de Uberlândia, Avenida Pará, 1720, Bloco 2B, Sala 24, Campus Umuarama, 38400-902 Uberlândia, MG, Brasil. Tel.: +55 34-3218-2255. Fax.: +55-34-3218-2279. e-mail: carlosjsoares@umuarama.ufu.br 
(3), preferred information is derived from prospective comparative clinical studies, especially randomized, controlled clinical trials.

Several factors are involved in the survival rate of restorative procedures in endodontically treated teeth. The aim of this study was to review the retrospective and prospective clinical studies, limited to adult humans receiving cast metal or fiber post restorations in permanent teeth with respect to restoration survival and modalities of failure.

\section{MATERIAL AND METHODS}

\section{Search Strategy}

Electronic searches of the literature were performed in MEDLINE and The Cochrane Library by crossing the key words: "Fiber post and clinical study", "Fiber post and clinical evaluation", "Cast post-and-core and clinical study", and "Root post and retrospective survival study" (Table 1). The cut-off period was from December 1990 through the end of December 2010. Only English-language papers were eligible.

The literature search aimed to find answers to the following clinical questions:

1. Do fiber posts have clinical survival similar to metallic posts?

2. Under what conditions of remaining tooth structure can each post system are indicated?

3. What is the most common type of failure for teeth restored using metallic or fiber post?

\section{Selection of Studies}

In a first screening step, the two reviewers independently evaluated titles and abstracts of

Table 1. Combinations of key words used for the search strategy.

\begin{tabular}{lcc}
\hline Key words & $\begin{array}{c}\text { Total of } \\
\text { papers }\end{array}$ & $\begin{array}{c}\text { Selected } \\
\text { papers }\end{array}$ \\
\hline Fiber post and clinical study & 252 & 13 \\
$\begin{array}{l}\text { Fiber post and clinical } \\
\text { evaluation }\end{array}$ & 99 & 2 \\
$\begin{array}{l}\text { Cast post-and-core and clinical } \\
\text { study }\end{array}$ & 60 & 5 \\
$\begin{array}{l}\text { Root post and retrospective } \\
\text { survival study }\end{array}$ & 25 & 2 \\
\hline
\end{tabular}

retrospective and prospective studies retrieved from the electronic search using the key words. Repeated papers obtained from different key words were considered only once. The full-text papers were then obtained and reviewed based on the following criteria:

Inclusion criteria: clinical follow-up of at least 1 year: minimum sample size of 30 patients; restorative procedures and materials described in detail; survival rate and patient characteristics indicated at baseline in prospective studies; locations of restored teeth; more recent publication of the same study.

Exclusion criteria: case reports; laboratory studies; use of ceramic posts; review articles.

Disagreement between reviewers was solved by discussion. When a consensus was not reached, a third review author was consulted. All studies meeting the inclusion criteria and none of the exclusion criteria underwent validity assessment and data extraction. Only 22 of the 436 papers were used in this study.

\section{Data Extraction and Presentation}

Data extraction was performed with the help of a data extraction form piloted on several papers. The following data were recorded: (i) reference name; (ii) year of publication; (iii) evaluation time in days; (iv) type of post; (v) number of samples; (vi) localization of tooth; and (vii) comments about success and failure rates (Tables 2 and 3 ).

\section{RESULTS}

Twenty-two clinical papers were selected. The majority were prospective studies $(\mathrm{n}=16)$ and 6 were retrospective cohort studies. The sample size ranged from 31 patients (18) to 911 (10) patients.

Two papers were excluded from this review because they were the same research but on different evaluation times, and because of this, we used the most recent surveys $(10,19)$. One paper was excluded because did not present clearly the number of patients, only recorded post number (20). Drop-out rates were only reported by few studies, being 2-3\% (9), 9\% (12), 11$32 \%$ (3) and $15.55 \%$ (21), these patients had either died or could not be found because either their home address or their name had changed or no compliance the call.

In the included studies (Table 2 and 3), the main outcomes evaluated were endodontic and periodontal failure, root fractures, tooth loss, post or restoration 
debonding and caries, the same as identified in a review article by Goodacre et al. (22). Ferrari et al. (9) compared carbon fiber post with cast post-and-core and observed clinical success rates of $95 \%$ and $84 \%$, respectively. The most important failure found of the first was periapical lesions $(2 \%)$ and root fractures to cast posts $(9 \%)$. In he same way, Glazer et al. (23) showed $7.7 \%$ of failures with periapical lesions occurring in about $50 \%$ of carbon fiber posts. Grandini et al. (4), Ferrari et al. (10) and
Jung et al. (8) observed the same type of failure in teeth restored with fiber posts over 30 months, 7-11 years and 5-10 years of clinical service, respectively. Mannocci et al. (24) reported failures involving caries or root fractures, but the fractures were found in teeth restored with amalgam without post.

Piovesan et al. (5) evaluated 97 months of clinical service and found fiber post fracture as the main failure. Similar result was found by Naumann et al. $(13,19)$. In

Table 2. Retrospective post studies.

\begin{tabular}{|c|c|c|c|}
\hline Authors & During & $\mathrm{N}^{*}$ & Post systems \\
\hline Ferrari et al., 2000 & 4 years & 200 & Fiber post and cast post-and-core \\
\hline Balkenhol et al., 2007 & 10 years & 802 & Cast post-and-core \\
\hline Fokkinga et al., 2007 & 17 years & 307 & $\begin{array}{c}\text { Cast post-and-core, prefabricated metal post and resin composite core, } \\
\text { Post-free all-composite core }\end{array}$ \\
\hline Jung et al., 2007 & $5-10$ years & 72 & Cast post-and-core and composite post \\
\hline Ferrari et al., 2007 & $7-11$ years & 985 & Fiber post \\
\hline Gomes-Polo et al., 2010 & 10 years & 112 & Cast post-and-core and titanium prefabricated post \\
\hline
\end{tabular}

*N=sample number.

Table 3. Prospective post studies.

\begin{tabular}{|c|c|c|c|}
\hline Authors & Duration & $\mathrm{N}^{*}$ & Post system \\
\hline Hatzikyriakos et al., , 1992 & 3 years & 154 & Screw post or gold post with resin core and cast post-and-core \\
\hline Glazer et al., 2000 & 4 years & 52 & Carbon fiber post \\
\hline Monticelli et al., 2003 & $2-3$ years & 225 & Fiber glass and carbon post \\
\hline Ellner et al., 2003 & 10 years & 50 & Cast post-and-core and prefabricated post \\
\hline Malferrari et al., 2003 & 30 months & 205 & Quartz fiber post \\
\hline Grandini et al., 2005 & 30 months & 100 & Fiber post \\
\hline Naumann et al., 2005 & 2 years & 105 & Fiber post \\
\hline Mannocci et al., 2005 & 5 years & 219 & Fiber post \\
\hline Creugers et al., 2005 & 5 years & 319 & Metallic post \\
\hline Naumann et al., 2007 & 3 years & 91 & Titanium and fiber post \\
\hline Cagidiaco et al., 2007 & 2 years & 162 & Fiber post \\
\hline Schmitter et al., 2007 & 2 years & 100 & Titanium and fiber post \\
\hline Salvi et al., 2007 & 4 years & 325 & Cast post-and-core and titanium post \\
\hline Piovesan et al., 2007 & 97 months & 69 & Polyethylene fiber reinforced \\
\hline Naumann et al., 2008 & 5-79 months & 149 & Fiber post \\
\hline Bitter et al., 2009 & 32 months & 120 & Quartz fiber post \\
\hline
\end{tabular}

$* \mathrm{~N}=$ sample number. 
another study, however, Naumann et al. (14) did not observe any failures after 24 to 36 months following titanium $v s$ glass fiber posts placement. On the other hand, Malferrari et al. (15) and Cagidiaco et al. (25) observed $1.7 \%$ and $4.3 \%$ of fiber posts debonding within 30 months, respectively. Monticelli et al. (17), after 2-3 years found $6.2 \%$ of debonding. Similar failure rate was observed by Ellner et al. (18) comparing cast posts with prefabricated metal posts over 10 years, but they did not cite the types of failure. For some authors $(3,7,16)$, loss of post retention was the main type of failure, similarly as reported by Balkenhol et al. (6), who described frequent occurrence of failures during the first two years following insertion of the metallic post.

Regarding the comparison between fiber and metallic posts, Schmitter et al. (12) found that the survival rate of screw metallic post was significantly lower than that of glass fiber posts, correlating tooth extractions with unrestorable root fractures, resulting in $63.63 \%$ of all failures. Likewise, Salvi et al. (2) found frequent complications that included root fractures (6.2\%) associated with prefabricated titanium posts. However, Hatzikyriakos et al. (26) observed no significant difference among metallic posts after three years.

The influence of the remaining coronal structure on the survival of roo-filled teeth was explained by some authors. Glazer et al. (23), Ellner et al. (18), Naumann et al. (14) and Bitter et al. (21) have indicated at least $2 \mathrm{~mm}$ of ferrule to post placement. Confirmatory evidence was provided by different authors $(3,10,16,17,25)$, who found a reduction of failures of postendodontic restorations when increasing the remaining dentin height, which adds to retention and provides a resistance form, enhancing the longevity of the restoration.

Another relevant but still controversial clinical aspect of endodontically treated teeth refers to tooth type. Gómez-Polo et al. (7) found the highest failure rate $(26.78 \%)$ for maxillary premolars. Naumann et al. (19) found that restorations placed in incisors or canines had about 3 times the failure rate of restorations placed in premolars or molars. On the other hand, Balkenhol et al. (6) concluded that the survival probability did not depend on the location of the tooth in the dental arch (anterior, premolar, molar) or the jaw (upper, lower), although Ferrari et al. (10) reported that dental arch and tooth position within the dental arch were significant risk factors for failure, with upper and posterior teeth being more likely to fail than lower and anterior teeth.

Regarding survival probability, the type of post-and-core system showed to have no influence (3), although estimation over time showed that the cumulative survival rate decreased gradually, being $94.6 \%$ after 5 years, $85.6 \%$ after 10 years, $70.5 \%$ after 15 years, and finally $60.4 \%$ after 18 years (7).

\section{DISCUSSION}

This survey examined the existing literature on the longitudinal clinical evaluation of post systems. It was observed that relatively few clinical studies have been carried out, presumably due to the greater of difficulty in conducting standardized studies in vivo. This literature review suggests that many endodontically treated teeth are not reinforced with metallic or fiber posts. The role of the post is only to support the abutment build-up material and, consequently, the final restoration $(2,9)$.

The definition of clinical success is based on the absence of negative findings at the final examination. In a prospective study design, many of the possibly involved variables are already controlled at the stage of case selection, and experimental groups can be made homogeneous in all but the variable under study. Such a study model, by limiting the effect of confounding factors, delivers more truthful, reliable, and, therefore, valuable information (17). Many retrospective clinical studies have been conducted regarding post-and-core systems, and the findings are stronger than had the same results been found without being able to control all these factors (2). Some of these factors mentioned above, show a relationship between the prognosis of post-endodontic restorations and factors such as the type of occlusion (27), tooth position in the dental arch, crown placement, or type of abutment $(13,26)$.

With regard to the comparison of types of systems, many studies had similar results, but metal posts were associated with more unfavorable complications, namely root fracture $(2,3,8,9,12,18)$. It was suggested that a post should have a modulus of elasticity similar to that of dentin for a more uniform distribution of stress along the post length $(4,12-14,17)$. Parallel-sided, threaded posts offer the greatest resistance to dislodgment from the root canal, and cemented parallel-sided posts have been found to be more retentive than cemented tapered posts. Less stress is concentrated into the root because there is less of a wedging effect; consequently, this type of post results in fewer root fractures than tapered posts. On the other hand, tapered posts require less dentin removal, because most roots are tapered, and they are primarily 
indicated for use in teeth with thin roots and complex morphology (28). Additionally, the parallel-shaped serrated post has a failure rate that is almost three times higher than that of a tapered post system (13).

The association between dental geometry and position of the tooth in the dental arch and the selection of the type of retainer used in endodontically treated teeth has actually been slightly commented on but is still controversial. Restorations placed in incisors or canines had a failure rate about three times higher than that of restorations placed in premolars or molars (13). These findings may be explained by the higher horizontal forces causing tension stress on anterior teeth, compared with a more perpendicular compressive force vector for posterior teeth $(12,13)$. The use of carbonreinforced resin posts in premolars, especially in lower premolars, may be associated with a higher failure rate and shorter longevity than in anterior teeth (22). King et al. (29) reported that the strength of carbon fiber posts was decreased by as much as one third when soaked in water for $24 \mathrm{~h}$ prior to testing. It is, therefore, possible that during clinical function the carbon fiber-reinforced posts absorbed water slowly from the surrounding tissues by diffusion, resulting in a reduction in strength which may have contributed to their early clinical failure (29). Type of final restoration and presence of adjacent teeth were found to be significant predictors of failure rates in root-filled teeth with glass fiber-reinforced posts (13).

Most clinical studies found that failures occurring in cast post-and-cores are catastrophic fractures $(9,10,15,30)$. One of the reasons for root fracture is that, in the cast post-and-cores, the stresses are concentrated in uncontrolled areas where a fracture can start (4). Another reason may be that if the cast post-and-core has retention (due to friction along root walls which can transmit stress directly to the root structure, corresponding with the area where dentin walls are thinner and, consequently, less resistant), then the fracture can occur $(9,10,13,19)$.

For fiber-reinforced posts, the failures observed are periapical failures, debonding of posts caused mainly by failure in cementation or during removal of temporary restorations $(9,17)$. However, these are easily solved with a new cementation, prolonging the function for a long time $(9,10,13,17,23)$. On the other hand, the presence of the post may not necessarily be the factor that generates the endodontic faults (3), but the periapical condition prior to treatment, the apical limit, and the quality of filling could be considered the main factors influencing the success of treatment. Besides that high-quality root canal treatment and the appropriate restorative protocol to each specific clinical situation are important for high survival and low complication rates of single-and multirooted root-filled teeth (2).

Mechanical failure of restored teeth with fiberreinforced posts can be related to the amount of residual coronal structure $(9,10,17,31)$. A prospective study (16) showed that type of post-and-core was not relevant with respect to survival, but the amount of remaining dentin after preparation influenced significantly the longevity of post-and-core restoration. A preparation design that involves the cervical portion of the tooth may resist lateral forces better than a shoulder preparation (31). The ferrule adds some retention, but primarily provides a resistance from and enhances longevity to the endodontically treated teeth restored with post and crown (6,27). A minimum of $1.5-2 \mathrm{~mm}$ ferrule of dentin has been consistently described as an essential factor for the success of fiber post systems $(3,15,23,30)$. In the absence of coronal ferrule, Fokkinga et al. (3) suggested to use cast post-and-cores.

Tables 2 and 3 present a summary of the clinical studies evaluated in this survey, which demonstrated that the different post systems can provide good clinical performance. The most important factors are to make an appropriate selection of the post system, use the cementation material accurately, and properly evaluate the remaining root filling. In addition, it is important to assess the presence or absence of ferrule and determine which type of final restoration will be necessary to increase the longevity and prevent later failures.

The review of the available clinical evidence on the use of post systems for the restoration of endodontically treated teeth leads to the following conclusions: an adequate selection of teeth and post system must be made; minimal amount of existing tooth structure should be removed; a ferrule must be present for safe indication of the fiber posts; fiber glass posts have demonstrated good survival in clinical studies, with similar performance to metallic posts; metallic posts have good clinical survival, but the associated failures are mostly irreversible, unlike what happens with the glass fiber posts.

\section{RESUMO}

O objetivo foi realizar revisão de estudos clínicos retrospectivos e prospectivos de pinos e núcleos metálicos e pinos de fibra em relação à taxa de sobrevivência e tipo de falhas prevalentes. A revisão de literatura foi realizada utilizando a base de dados 
MEDLINE com os seguintes termos para pesquisa: "Pino de fibra e estudo clínico", "Pino de fibra e avaliação clínica", "Pinos e núcleos metálicos e estudo clínico", "Pinos intra-radiculares e estudo clínicos retrospectivos". O período avaliado foi de Dezembro de 1990 até o final de Dezembro de 2010. Vários fatores biológicos, mecânicos e estéticos estão envolvidos na taxa de sobrevivência do procedimento restaurador de dentes tratados endodonticamente. A seleção do pino deve satisfazer e otimizar esses fatores. Dados com base em estudos clínicos de longo prazo são essenciais para o clínico geral na tomada de decisões. Adequada indicação na seleção do sistema de pino devem ser feitas. Adicionalmente, desgaste mínimo da estrutura dentária existente deve ser priorizado. A presença de férula deve estar presente para garantir e melhorar a previsibilidade de pinos de fibra. Pinos de fibra de vidro têm demonstrado boa sobrevivência em estudos clínicos, com desempenho semelhante aos pinos metálicos e núcleos moldados e fundidos. Retentores metálicos apresentam boa sobrevivência clínica, no entanto as falhas envolvidas são em sua maioria irreversíveis, ao contrário do que acontece com os pinos de fibra de vidro.

\section{REFERENCES}

1. Heydecke G, Peters MC. The restoration of endodontically treated, single-rooted teeth with cast or direct posts and cores: a systematic review. J Prosthet Dent 2002;87:380-386.

2. Salvi GE, Siegrist Guldener BE, Amstad T, Joss A, Lang NP. Clinical evaluation of root filled teeth restored with or without post-and-coresystems in a specialist practice setting. Int Endod J 2007;40:209-215.

3. Fokkinga Wietske A, Kreulen Cees M, Bronkhorst Ewald M, Creugers Nico HJ. Up to 17-year controlled clinical study on postand-cores and covering crowns. J Dent 2007;35:778-786.

4. Grandini S, Goracci C, Tay FR, Grandini R, Ferrari M. Clinical evaluation of the use of fiber posts and direct resin restorations for endodontically treated teeth. Int J Prosthodont 2005;18:399-404.

5. Piovesan EM, Demarco FF, Cenci MS, Pereira-Cenci T. Survival rates of endodontically treated teeth restored with fiber-reinforced custom posts and cores: a 97-month study. Int J Prosthodont 2007;20:633-639.

6. Balkenhol M, Wöstmann B, Rein C, Ferger P. Survival time of cast post and cores: a 10-year retrospective study. J Dent 2007;35:5058.

7. Gómez-Polo M, Llidó B, Rivero A, Del Río J, Celemín A. A 10year retrospective study of the survival rate of teeth restored with metal prefabricated posts versus cast metal posts and cores. J Dent 2010;38:916-920.

8. Jung RE, Kalkstein O, Sailer I, Roos M, Hämmerle CH. A comparison of composite post buildups and cast gold post-andcore buildups for the restoration of nonvital teeth after 5 to 10 years. Int J Prosthodont 2007;20:63-69.

9. Ferrari M, Vichi A, Garcia-Godoy F. Clinical evaluation of fiberreinforced epoxy resin posts and cast post and cores. Am J Dent 2000;13:15B-18B.

10. Ferrari M, Cagidiaco MC, Goracci C, Vichi A, Mason PN, Radovic I, et al.. Long-term retrospective study of the clinical performance of fiber posts. Am J Dent 2007;20:287-291.

11. Bateman G, Ricketts DN, Saunders WP. Fibre-based post systems: a review. Br Dent J 2003;195:43-48.

12. Schmitter M, Rammelsberg P, Gabbert O, Ohlmann B. Influence of clinical baseline findings on the survival of 2 post systems: a randomized clinical trial. Int J Prosthodont 2007;20:173-178.
13. Naumann M, Blankenstein F, Dietrich T. Survival of glass fibre reinforced composite post restorations after 2 years-an observational clinical study. J Dent 2005;33:305-312.

14. Naumann M, Sterzenbac G, Alexandra F, Dietrich T. Randomized controlled clinical pilot trial of titanium vs. glass fiber prefabricated posts: preliminary results after up to 3 years. Int $\mathrm{J}$ Prosthodont 2007;20:499-503.

15. Malferrari S, Monaco C, Scotti R. Clinical evaluation of teeth restored with quartz fiber-reinforced epoxy resin posts. Int J Prosthodont 2003;16:39-44.

16. Creugers NH, Mentink AG, Fokkinga WA, Kreulen CM. 5-year follow-up of a prospective clinical study on various types of core restorations. Int J Prosthodont 2005; 18:34-39.

17. Monticelli F, Grandini S, Goracci C, Ferrari M. Clinical behavior of translucent-fiber posts: a 2-year prospective study. Int J Prosthodont 2003;16:593-596.

18. Ellner S, Bergendal T, Bergman B. Four post-and-core combinations as abutments for fixed single crowns: a prospective up to 10-year study. Int J Prosthodont 2003;16:249-254.

19. Naumann M, Reich S, Nothdurft FP, Beuer F, Schirrmeister JF, Dietrich T. Survival of glass fiber post restorations over 5 years. Am J Dent 2008;21:267-272.

20. Mehta SB, Millar BJ. A comparison of the survival of fibre posts cemented with two different composite resin systems. Br Dent J 2008;205:E23.

21. Bitter K, Noetzel J, Stamm O, Vaudt J, Meyer-Lueckel H, Neumann K, et al.. Randomized clinical trial comparing the effects of post placement on failure rate of postendodontic restorations: preliminary results of a mean period of 32 months. J Endod 2009;35:1477-1482.

22. Goodacre CJ, Bernal G, Rungcharassaeng K, Kan JY. Clinical complications in fixed prosthodontics. J Prosthet Dent 2003;90:3141.

23. Glazer B. Restoration of endodontically treated teeth with carbon fibre posts - a prospective study. J Can Dent Assoc 2000;66:613618.

24. Mannocci F, Qualtrough AJ, Worthington HV, Watson TF, Pitt Ford TR. Randomized clinical comparison of endodontically treated teeth restored with amalgam or with fiber posts and resin composite: five-year results. Oper Dent 2005;30:9-15.

25. Cagidiaco MC, Radovic I, Simonetti M, Tay F, Ferrari M. Clinical performance of fiber post restorations in endodontically treated teeth: 2-year results. Int J Prosthodont 2007;20:293-298.

26. Hatzikyriakos AH, Reisis GI, Tsingos N. A 3-year postoperative clinical evaluation of posts and cores beneath existing crowns. J Prosthet Dent 1992;67:454-458.

27. Torbjörner A, Fransson B. A literature review on the prosthetic treatment of structurally compromised teeth. Int J Prosthodont 2004; 17:369-376.

28. Schwartz RS, Robbins JW. Post placement and restoration of endodontically treated teeth: a literature review. J Endod 2004;30:289-301.

29. King PA, Setchell DJ, Rees JS. Clinical evaluation of a carbon fibre reinforced carbon endodontic post. J Oral Rehabil 2003;30:785789.

30. Cagidiaco MC, Goracci C, Garcia-Godoy F, Ferrari M. Clinical studies of fiber posts: a literature review. Int J Prosthodont 2008;21:328-336.

31. Jotkowitz A, Samet N. Rethinking ferrule-a new approach to an old dilemma. Br Dent J 2010;209:25-33.

Received June 14, 2011 Accepted January 30, 2012 